\title{
Effect of quality work life relationship on occupational stresses among Bu-alisina university staff in Hamadan province, IR Iran
}

\author{
Behzad Imani $^{1 *}$, Arezo Karampourian ${ }^{2}$, Zohreh Ghomian $^{3}$, Mahmoud Taajobi $^{4}$ \\ ${ }^{1}$ Hamedan University of medical sciences, Hamedan \\ ${ }^{2}$ Shahid Beheshti University of Medical Sciences \\ ${ }^{3}$ Department of Health, Safety and Environment, Shahid Beheshti University of Medical Sciences, Tehran, Iran \\ ${ }^{4} \mathrm{Bu}$-Ali Sina University .Hamedan .Iran \\ Accepted 4 September, 2016
}

\begin{abstract}
Quality of Work Life (QWL) is a comprehensive program leading to promotion of productivity, performance and satisfaction of staffs. Occupational stress is also an individual's physical ,mental and emotional reactions which are experienced due to working life needs and changes therefore, this research aims to determine the relationship of QWL and occupational stresses of Bu-Ali Sina university staff. The study is of cross sectionaldescriptive type carried out in 2012. The research population consisted Bu-Ali Sina university staffs of whom 178 were included in the research as sample. The data were collected through self-expression standard questionnaire of determining QWL and questionnaire of classification of individual's stress (Holms and Roy).These two questionnaires were distributed among the individuals simultaneously and after they were filled, they were collected. To test the hypotheses, Pearson correlation coefficient and Lambda test were used. The results showed that the level QWL in the population of the study was at the medium and there was a positive significant relationship between $Q W L$ and staff' education $(p=0.001)$ and between $Q W L$ and staffs' working experience $(p=0.044)$.Based on Pearson correlation test, there was obtained a significant relationship between score of QWL mean and mean of individuals' stress. $(p=.0 .004)$.In another word, the greater the individuals' QWL, the less they experience stress. Regarding the research findings and confirmation of relationship of QWL and occupational stress ,managers can improve the level of QWL through cooperative programs and team working ,making relationships and attention to personnel's needs and expectations, job enrichment and staff empowerment to reduce occupational stress and increase efficacy and productivity of human resource.
\end{abstract}

Keywords: QWL Occupational stress, satisfaction.

Introduction

In contemporary management, the concept of QWL has turned into a common social topical over the world (Martel and Dupuis 2006). QWL is a multi-faceted, relative concept influenced by time, place, and social and individual values and depends on individuals ' view and

${ }^{*}$ Corresponding Author email: behzadiman@yahoo.com approach to life at individual level (Saraji-Nasl and Dargahi 2006) so that QWL can be classified into two categories ;objective and subjective (Flippo 2008). In fact, QWL is a multidimensional structure containing concepts such as treatment services and welfare. In fact, QWL has a multidimensional structure containing concepts such as welfare actions and treatment services, incentive schemes, job proportion, job security, job design, job importance and individual status in organization, Provision of growth participation in 
decision-making, conflict and job ambiguity reduction, and reward systems (Saraji-Nasl and Dargahi 2006). In the past few decades, individual life (non-working) was focused on. (Mohebali 2005), while proponents of QWL theory search for systems and programs to help the staff make a balance between working life and personal life (Akdere M (2006). The program of QWL consists of any improvement in organizational culture which promotes growth of individuals in organization. (Martocchio et al (2009) .It means a process by which all organization members affect the decisions which influence their job and environment through open and appropriate communication channels. Therefore, they become more satisfied with their job and work stress decreases. (Gordon (1993). The research findings show that implementation of this program reduces the number of staffs' complaints, absenteeism rate, regulatory actions, and increase staffs' positive attitude and their participation in suggestion system program. (Shareef and Reginald 2003). On the other hand, meeting the staff needs leads to improvement and long term efficacy of organization (Danna and Griffin, (1999). Dana and Griffin (1999) believe that QWL acts as a pyramid in which life satisfaction (top), job satisfaction (middle) and satisfaction with other work-related aspects such as salary, coworkers and observers. Consequently, the domain of QWL goes beyond the job satisfaction (CheRroso, 2006). Nowadays, most of experimental researches carried out on QWL have affirmed new prospective of job stresses and job-related concepts. (Holmes, 2001). One of the factors influencing the individuals' performance in organizations is stress which threatens the health of most people. (Rezaian A (2004) Therefore, stress has become one of the main topics in organizational behavior (Lee and Wong (2002). Stress is physical, mental and emotional reactions which are experienced due to individuals' life needs change in various scales. The individuals' response to life change varies. Positive stress can be a motivator while negative stress can be created when these changes defeat the person. (Randall and Elizabeth (1994).Stress is directly related to job satisfaction and person's performance, and is believed to be one of the influencing factors on health, safety and QWL. Damage compensation and costs related to diseases and complications from work stress have forced managers to have a special attention to stress. (Sundberg and Palmqvist (2009).

\section{Methodology}

This is a cross sectional-descriptive study of correlative type. The research sample is all the staffs of Bu-Ali Sina University of whom 178 were chosen to participate inthe research voluntarily. Data were collected through standard questionnaire of QWL and that of classifying individual's stress (Holmes and Rahe, 1997). QWL questionnaire was developed from walton's components with some modifications. Holmes and Rahe (1997) showed that the events which change the life can make individuals susceptible to mental diseases.QWL questionnaire consisted of two parts: the first part contains individual features such as sex, education, marital status, age and working experience and the second part contains 21 items in four-rank scale classifying QWL in very low, low, relative, complete. The staffs had to answer the questions. The stress classification questionnaire had 45 questions to which the respondents marked the stresses he/she had in the previous years. Finally, the total score of stress for the previous year was calculated. To determine the reliability of the questionnaire, Chronbach alpha method was used with the result obtained to be 0.92 for job stress and 0.78 for QWL questionnaire. Data were analyzed with descriptive and inferential statistics methods and pearson correlation coefficient and lambda test were used to assess the relationship of job stress and dimensions of QWL. Spss16 was used to do the analysis.

\section{Results}

Based on the results, majority of participants were made $(67.4 \%)$, with bachelor degree $(41 \%)$ and married $(82 \%)$. Most of the participants were in the age range of 30-40 years old $(58.4 \%)$ with working experience of $10-20$ years $(28.7 \%)$. (Table 1$)$.Lambda test showed that the variable of QWL does not have a significant relationship with sex, marital status and age while the average of QWL has a significant correlation with education level and, working experience (table 2).Regarding the results of staffs' QWL score average was medium (2.8) and staffs' stress level was high (167.75).Based on pearson correlation test in table 3 , there is a significant relationship between QWL scores and staffs' job stress. From graph 1, this relationship is shown to be linearly inverse, meaning increasing the job stress reduces QWL.

\section{Discussion}

The present study examines the relationship between some individual features and stress with QWL. The findings of this study are in some cases compatible and in some incompatible with other international studies. Based on the findings of this study, there was not a significant relationship between sex and QWL. The results of the study by Sundberg and Palmquist (2009) and Kintner (2008) confirm this. They did not find any relationship between sex and QWL (16-1). In the present research, there was a significant relationship between $\mathrm{QWL}$ and education level $[\mathrm{p}=0.001]$. Increasing education level and having higher job status made the staffs' QWL 
050 E3 J. Sci. Res.

Table 1: Frequency distribution of research units

\begin{tabular}{lccccc}
\hline Sum & Variables & Frequency percent & No & No & Percent \\
\hline Sex & female & $32 / 6$ & 58 & 178 & 100 \\
Education & male & $67 / 4$ & 120 & & 100 \\
& Under diploma & $4 / 5$ & 8 & 178 & \\
& diploma & $15 / 7$ & 28 & & \\
& Association of art & $25 / 3$ & 45 & & \\
& bachelor & 41 & 73 & & \\
Marital & postgraduates & $13 / 5$ & 24 & & \\
status & married & 82 & 146 & 178 & 100 \\
Age(years) & single & 18 & 32 & & \\
& $20-30$ & $18 / 5$ & 33 & 178 & 100 \\
& $30-40$ & $58 / 4$ & 104 & & \\
Working & $40-50$ & 23 & 41 & & \\
experience & $>5$ & $20 / 2$ & 36 & 178 & 100 \\
years & $5-10$ & $26 / 4$ & 47 & & \\
& $10-20$ & $28 / 7$ & 51 & & \\
& $20-30$ & $24 / 7$ & 44 & & \\
\hline
\end{tabular}

Table 2: comparison of $Q W L$ in terms of respective variables

\begin{tabular}{|c|c|c|c|c|}
\hline \multirow{2}{*}{ Variables } & \multicolumn{4}{|c|}{ QWL } \\
\hline & variables & Sd & Average & Test results \\
\hline \multirow[t]{3}{*}{ Sex } & Male & $0 / 10$ & $2 / 73$ & \multirow{3}{*}{$\begin{array}{c}\text { Lambda value }=.135 \\
P=.215\end{array}$} \\
\hline & Female & $0 / 83$ & $3 / 03$ & \\
\hline & Under diploma & $0 / 15$ & $1 / 83$ & \\
\hline \multirow{3}{*}{ Education } & Diploma & $0 / 10$ & $2 / 80$ & \multirow{3}{*}{$\begin{array}{c}\text { Lambda value }=.333 \\
\qquad=.001\end{array}$} \\
\hline & Association of art & $1 / 46$ & $2 / 78$ & \\
\hline & Post graduates & 0/09 & 2/91 & \\
\hline \multirow[t]{3}{*}{ Marital status } & Married & $0 / 11$ & $2 / 90$ & \multirow{2}{*}{$\begin{array}{l}\text { Lambda value }=.000 \\
\qquad \begin{array}{l}P=1\end{array}\end{array}$} \\
\hline & Single & $0 / 87$ & $2 / 12$ & \\
\hline & $20-30$ & $0 / 30$ & $2 / 41$ & \multirow{4}{*}{$\begin{array}{c}\text { Lambda value }=.178 \\
\qquad \begin{array}{l}\mathrm{P}=.131\end{array}\end{array}$} \\
\hline \multirow[t]{3}{*}{ Age(years) } & $30-40$ & 0/03 & $2 / 86$ & \\
\hline & $40-50$ & $0 / 11$ & $3 / 11$ & \\
\hline & $>5$ & 0/08 & $2 / 12$ & \\
\hline Working & $5-10$ & 0/08 & $2 / 80$ & \multirow{3}{*}{$\begin{array}{c}\text { Lambda value }=.217 \\
\qquad \begin{array}{l}\mathrm{P}=.041\end{array}\end{array}$} \\
\hline \multirow{2}{*}{ experience years } & $10-20$ & 0/07 & $2 / 01$ & \\
\hline & $20-30$ & $1 / 01$ & $3 / 14$ & \\
\hline
\end{tabular}

Table 3: comparison of relationship between QWL scores and staffs` job stress

\begin{tabular}{lccc}
\hline & SD & Average & Pearson correlation \\
\cline { 2 - 4 } QWL & $0 / 001$ & $2 / 8$ & \multirow{2}{*}{$\mathrm{P}=.000$} \\
Job stress & $0 / 908$ & $167 / 75$ & \\
\hline
\end{tabular}

more favorable. In general, having an occupation helped the people to promote their QWL. As Kintner (2008) stated the employed have better QWL than the unemployed. (Kalpaklioglu and Baccloplu (2008). Among the employed, those with higher level of education can have better QWL due to better job. Kalpakalioglu and Baccloplu (2008) found a significant relationship between education level and QWL (Alvin et al., 2009). 
In contrast to our study, in a study by Kalpakalioglu and Baccloplu (2008) there was a significant relationship between age and QWL of asthma patients. (Alvin et al (2009). It seems that this difference originates from the healthy and patient population in the studies. In our research, there was not observed any significant relationship between material status and QWL Alrin et al (2009) point out that supportive resources influence patients' conditions for recovery and the patients living alone have unfavorable QWL. (Lees and Kearns (2005).). the difference is due to the effects of marital status on QWL compared with the QWL in disease. The results of our study showing a more favorable QWL with the increase of staffs' working experience is consistent with that of Leese and Keems (2005). They pointed the greater the working experience is, the greater the satisfaction and QWL for staffs. (Khaghanizadeh et al (2008).In this research, there was seen to be an inverse linear relationship between staffs' QWL scores and job stress. $(p=0.000)$. Increasing staffs' job stress reduces the QWL and vice versa. The study of Khaghani Zadeh et al (2008) shows there is a significant inverse relationship between job stress and QWL in that every unit of increase in staffs' job stress score reduced their QWL score at 0.3 unit.

\section{Conclusion}

Regarding the research findings and confirmation of inverse relationship of QWL and occupational stress, managers can improve the level of QWL through cooperative programs and team working ,making relationships and attention to personnel's needs and expectations ,job enrichment and staff empowerment to reduce occupational stress and increase efficacy and productivity of human resource while providing opportunity for staff to continue their education during their job or job-related training programs.

\section{References}

Akdere M (2006)."Improving quality of work - life implications for Hyman resources"; Bus. Rev 1:173.

Alvin C, Picinin I, Camargos P, Lasmar L, Ibiapina C, Fontes M (2009). Quality of life in asthmatic adolescent: an overall evalution disease control. J Asthma. 46(2):186-190.

CheRroso R (2006)."An analysis of quality of work life (QWL) and career-related variables ".American J. Appl. Sci. 12: 2151-2159

Danna K, Griffin RW (1999). "Health and wellbeing in the work place. A review and synthesis of the literature" J. Manage. 12: 375-384.

Flippo EB (2008). Personal management. Sixth edition، Mc graw-Hill international editions. Professional psychology. (13 ): 293-301.

Gordon JR (1993). A Diagnostic approach to organizational behavior; Forth Edition، Allyn and bacon.

Holmes S (2001). Work related stress a brief review. J. Res. Soc. Health. 121(4): 230-235.

Kalpaklioglu AF, Baccloplu A (2008). Evaluation of quality of life: Impact of allergic rhinitis on asthma. J. Investin. Allergolclinimmunol. 18(3):168-173.
Khaghanizadeh M, Ebadi A, Sirati M, Rahmani M (2008). The relationship between job stress and quality of work life of nurses in selected hospitals of the Armed Forces. Military Medicine. 10:175184.

Kintner E (2008). Development and preliminary evaluation of the participation in life activities scale for children and adolescents with asthema: an instrument development study. Health qual life out comes. 6(37).doi:1186/1477-7525.

Lee I, Wong H (2002). Occupational stress and related factor in public nurses. Nursing Res. 10(4): 253-260.

Lees M, Kearns S (2005). Improving work life quality: A diagnostic approach model. www.longwoods.com.

Martel JP, Dupuis G (2006). Quality of work life: Theoretical and methodological problems, and presentation of new model and measuring instrument. Social Indicators Research. 77(2):333-368.

Martocchio J, Liao H, Joshi A (2009). Research in Personnel and Human Resources Management.

Mohebali D (2005). 'The better work life: Afactor in increasing productivity '; Quart. J. Manage. Studi. 13(14): 54.

Randall RR, Elizabeth MA (1994). Intervention in Occupational Stress: A Handbook of Counseling for Stress at Work. SAGE Publications, Jul 28.

Rezaian A (2004). Stress Management (Management of Advanced Organizational Behavior). Organization of the reading and writing books and Humanities: Tehran.1-6.

Saraji-Nasl G, Dargahi H (2006). Study of quality of work life (QWL)"; Iranian J. Publ. Health. 35(4): 8-14.

Shareef، Reginald (2003). QWL programs facilitate change. Personnel J. 69: 50-67.

Sundberg R, Palmqvist M (2009). Health related quality of life in young adult with asthma. Respir. Med. 103(10):1580-1585. 